\title{
Survey of health services satisfactions from NCD patients in Thailand
}

\author{
Onthida Khamsiriwong ${ }^{1^{*}}$, Noppon Choosri ${ }^{2}$, Pathathai Na Lumpoon ${ }^{3}$, Krid Thongbanjop ${ }^{4}$ \\ Supavas Sitthithanasakul ${ }^{5}$, Waritsara Jitmun ${ }^{6}$
}

1, 2, 3, 4, 5, 6 College of Arts Media and Technology, Chiang Mai University, Chiangmai, Thailand

\author{
Keywords \\ NCD patient \\ Patient satisfaction \\ NCD survey \\ Health service
}

Received: 6 August 2018

Accepted: 7 September 2018

Published: 11 October 2018

\begin{abstract}
Currently, there is no existing report revealing the satisfaction of healthcare services from NCD patients in Thailand. Despite that, many NCD patients have regular meetings with the doctor periodically. Therefore, our research question was that NCD patients have adequate satisfaction in utilizing healthcare services in Thailand. The crosssection survey was conducted among 414 NCD outpatients to investigate the satisfaction of NCD patients who are obtaining NCD medication services from one of the community hospitals in northern Thailand. A five-point rating scale measured satisfaction through accidental sampling. The study revealed the concurrence of NCD patients satisfied with almost all survey measures. Moreover, the expertise of the doctor and the NCD clinic location were received a high satisfaction score. In contrast, the low satisfaction from the survey is related to the time spending for waiting. Additionally, subgroup analysis showed that NCD elder patients communicated more relaxed and comfortable with the doctors. This research result from NCD patients can roughly define the quality of public healthcare service in Thailand as satisfying.
\end{abstract}

(C) 2018 The Author(s). Published by TAF Publishing.

\section{INTRODUCTION}

NCDs are neither the diseases that are infectious nor transmitted. On the contrary, they are possibly caused by a combination of genetic, physiological, environmental and behavior factors [1, 2]. The diseases affect many millions of people which causes premature mortality, disability, suffering, and loss of opportunity. Also they are known as chronic diseases because the nature of treatments usually requires continuous meet-up and monitoring [3,4]. NCDs are caused by many factors and they relate to lifestyle, working, and leaving quality so the patients can be treated not only by medication but also by modification of their behaviors. Normally, the NCD patients have to make a meet-up with the doctor periodically and in some cases, the patients are required going to the hospital for their entire life.

NCDs have become a serious global health problem [5]. According to the statistical evidence reported by WHO, NCDs were leading to the cause of death worldwide in 2016 [6]. They accounted for $71 \%$ of deaths which occurred globally [7]. In the same way, the death rate from NCDs in Thailand

\footnotetext{
*corresponding author: Onthida Khamsiriwong
}

†email: onthida.k@camt.info was $74 \%$ of all deaths as illustrated in Figure 1 [6]. Thai NCD deaths proportion is shown in Figure 2. Cardiovascular diseases (23\%) and other NCDs (23\%) took equal proportions and Cancers (18\%), Chronic respiratory diseases (6\%) and Diabetes (4\%) are less descending respectively [6].

The number of NCD deaths implies that major population of patients widely use healthcare services. Nevertheless, only a few studies reported the surveys of NCD patients when they are treated at a public hospital. Switzerland is one of the leading countries for healthcare support. It was reported that more than 80 percent of the population had a rather positive or very positive view of the health system in 2014 [8]. In India, there is a study on the satisfaction of people living with NCDs. Such a study was examined by a descriptive survey through structured interview among 200 subjects. The satisfaction was measured by the three points rating scales. Their findings indicated that the majority of subjects were highly satisfied with the healthcare services which they were obtaining from either government or private agencies [9]. 


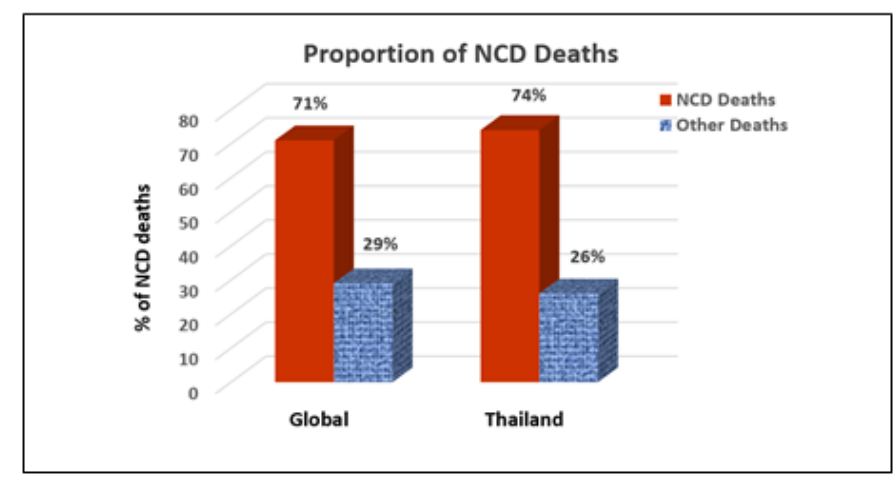

Fig. 1. Proportion of global and Thai NCD deaths in 2016

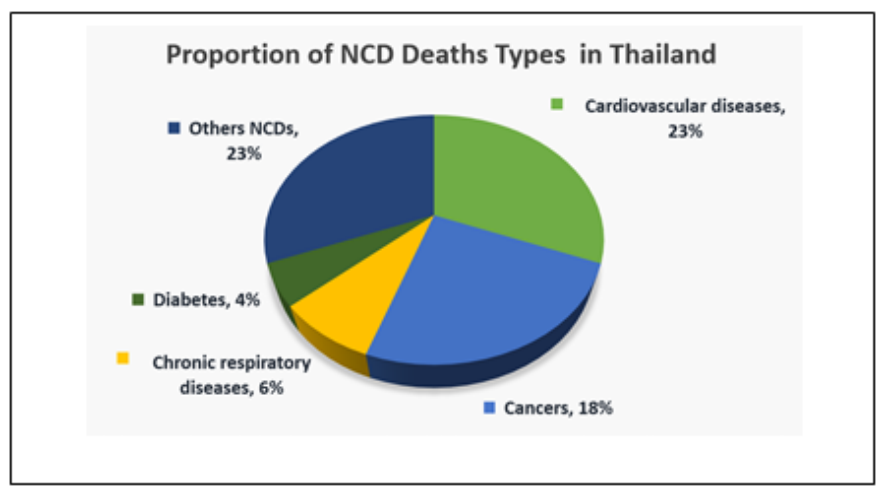

Fig. 2. Proportion of Thai NCD deaths types in 2016

However, no study reveals the effectiveness of the treatment of NCD patients in Thailand. Together with the fact that NCD patients have regular medical services at a hospital. This fact motivates us a significant question that NCD patients have adequate satisfaction in using clinical services in Thailand. This fact questioned us that NCD patients have adequate satisfaction levels when they are obtaining treatment services in Thailand. The research from [10] mentioned patient satisfaction is a very effective indicator that affects clinical outcomes, patient retention, and medical malpractice claims as well as they confirmed that the quality of health care is measured by the patient satisfaction.

This study employs survey research to measure the satisfaction of NCD patients who are treated in Thai healthcare medical clinics. The advantages of this study are twofold. The first is NCD patients contribute to the largest number of patients who regularly use medical services in the Thai healthcare system. Observing their attitudes and opinions through this survey can roughly reflect the big picture of the quality of healthcare service in Thailand. Second, being required regular hospitalization means if they are unhappy with healthcare or other related services, patients can be frustrated to attend the regular meet-up. This will directly affect the quality of NCD treatments.
This research aims to answer the question regarding the general satisfaction of NCD patients from using medication services at the hospital. We also would like to explore that demographic background of patient correlates with their satisfaction of using clinical services.

The organization of this paper is as follows, Section 2 justifies the case study of this research. Section 3 outlines the materials and methods. In Section 4, we report the survey results and Section 5 is our discussion and conclusion.

\section{CASE STUDY : KOKHA HOSPITAL}

This research was conducted at the Kokha hospital in Lampang province, the north of Thailand. The justification of conducting a field survey at this hospital in this province is that Lampang province is one of the areas in Thailand having a vast volume of NCD patients. Additionally, Lampang province identified NCDs as a first priority health problem [11]. From the healthcare classification of Thailand, Kokha is a community hospital for referral patients or Middle-level Hospital (M2) [12]. As illustrated in Figure 3, the role of Kokha hospital is located in the mid of the national healthcare system, bridging between community healthcare and larger scale healthcare together. This making Kokha hospital takes a part of an interchangeable unit to manage both inbound and outbound patients over the region. 


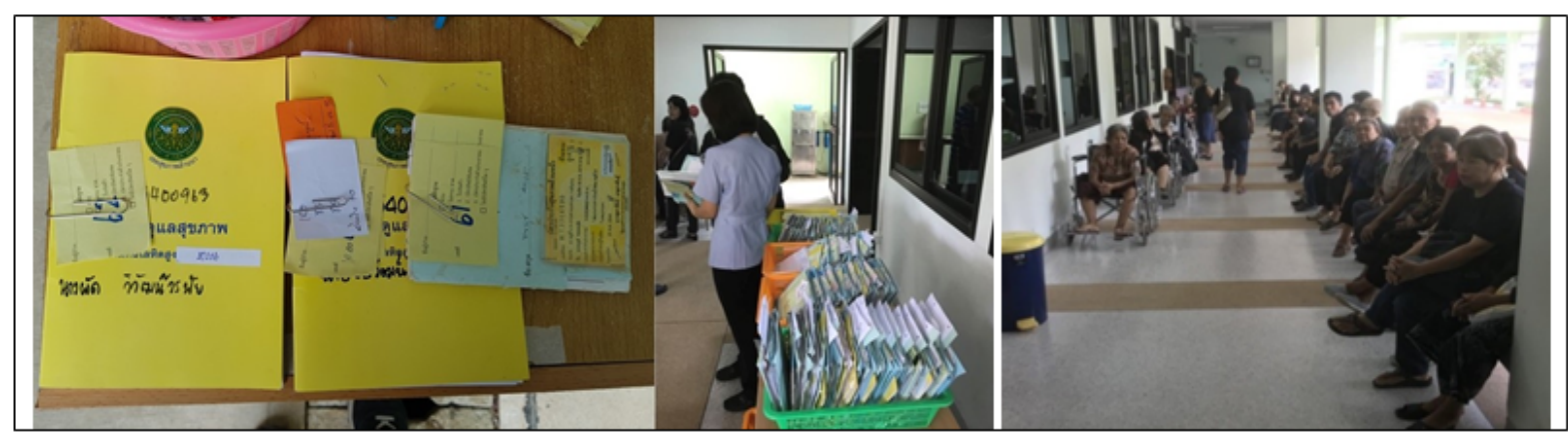

Fig. 3. The role of Kokha Hospital

Kokha hospital supports an inbound refer for 9 local health cares and directly provide healthcare services for people in the district. The average of NCD outpatients is Figure 5. Manual queuing and process management 150-160 per day. Hence, they established the NCD clinic in order to provide healthcare services, especially for the main NCD outpatients who have diabetes and high blood pressure (Figure 4) [12]. Specifically, primary observation from the field study indicated that most of the administrative and operational services are manually operated (Figure 5).

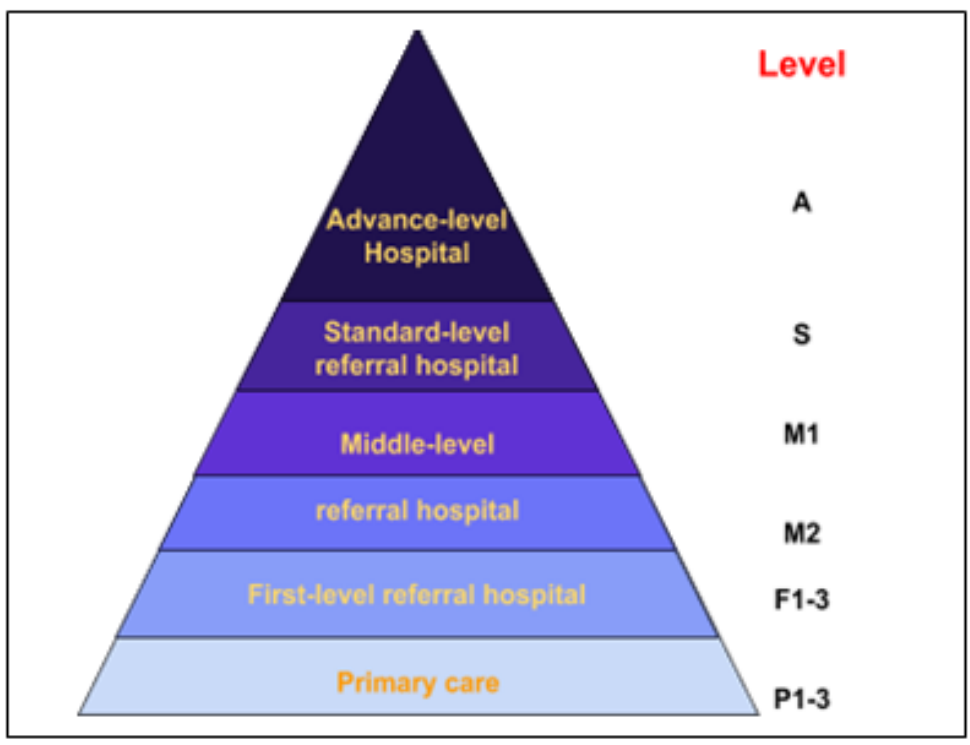

Fig. 4. Manual queuing and process management

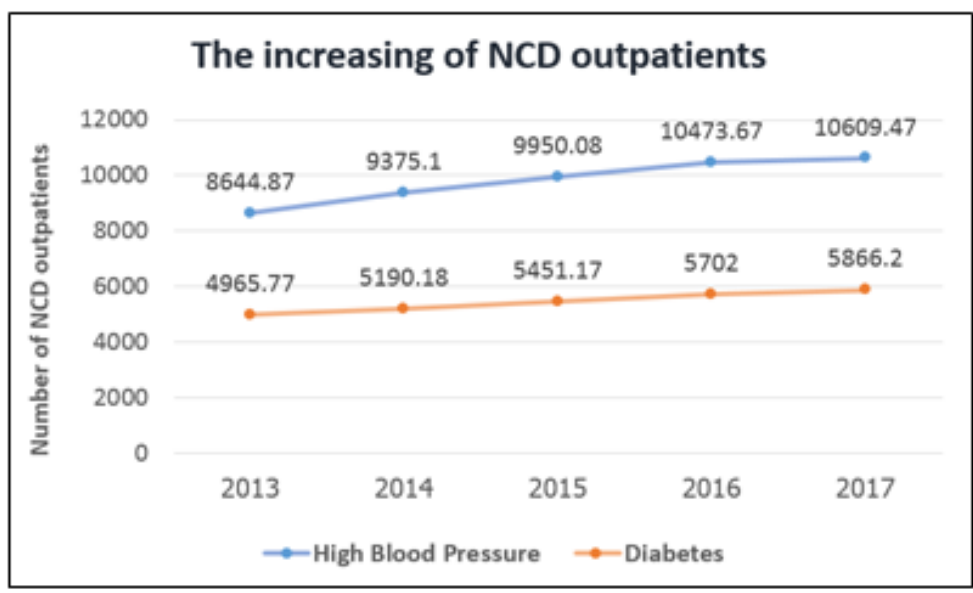

Fig. 5. The increasing of NCD outpatients of NCD clinic, Kokha hospital 


\section{MATERIALS AND METHODS}

A cross-sectional survey study was conducted among 414 NCD outpatients of NCD clinic, Kokha hospital. The questionnaires were distributed through the accidental sampling at the waiting areas. The surveys are collected within 2 weeks of October 2018. The questionnaire is started by asking the general demographic background of participants. For instance, gender, age, education, type of health insurance, a reason for taking treatment at this clinic, and frequency of visit. The questionnaire mainly asked participants to rate the satisfaction's score when using NCD clinic in 5 points [13]. Two major subsections are outlined further to divide the questions into 2 aspects.

Firstly, the satisfaction which focused on the existing processes and procedures. For example, the simple health service processes, the clearness of the procedures, the suitability of waiting time, the equitability of getting services, the suitability of the appointment process, and the promptness the pharmaceutical unit. Secondly, the satisfaction towards the general experience of using medical services. For instance, the expertise of doctors, the promptness of services, the excellence of medical equipment, the suitability of areas, and the ease of hospital access.

The questionnaire was validated by the experts from NCD clinic and obtained ethical clearance from the Institutional Ethical Committee, permission number E2561/12. Most of the participants was an elderly group who typically had difficulty to read the question or were visually impaired. The interviewer-administrator approach was mainly applied by the interviewers who assisted reading the question out loud and giving a choice for the participant to make a selection. For the case that patients came with a personal carer who is typically their relative, they assisted in communicating with the patients on the research behalf. In case patients have a problem with verbal communication or in the condition that they are unable to answer the question, the questionnaire conveys to ask the opinion of carer directly, such that the answer would ultimately rely on observations of hospital visit of the patients. The mean of satisfaction was analyzed and in some cases, the interpretation of the results was made by the Fisher's approach [14] which is shown in Table 1.

TABLE 1

SATISFACTION CLASSIFICATION ACCORDING TO CLASS INTERVAL

\begin{tabular}{lll}
\hline \hline Satisfaction Level & Mean & Class Interval \\
\hline 1 & $1.00-1.80$ & Very dissatisfied \\
2 & $1.81-2.60$ & Dissatisfied \\
3 & $2.61-3.40$ & Neutral \\
4 & $3.41-4.20$ & Satisfied \\
5 & $4.21-5.00$ & Very satisfied \\
\hline \hline
\end{tabular}

\section{RESULTS}

From 414 NCD participants, there were females $60.4 \%$ and the average age is 59.95 years old. The majority of them $(56.5 \%)$ received an elementary education for about $56.5 \%$. Among several availabilities of the national health campaign. Most of the patients claimed the benefit under the Universal Coverage Scheme (UCS) or known as '30 baht scheme' [15] for $55.1 \%$. The frequency of meeting-up the doctor was every 2 months approximately $44.7 \%$.

The result of the survey is shown in Table 2. It revealed that the satisfaction about the existing processes and procedures is relatively high. The highest satisfaction went to the clear procedural instruction at the clinic (4.17) and the lowest satisfaction went to the suitability of waiting time (3.68). However, the interpretation of the results using Fisher's method [14] indicated that there is no difference in terms of satisfaction. The patients were satisfied with the existing processes and procedures of the hospital.

By focusing on the general experience of using medical services, patients have very satisfied scales on the expertise of the doctor and the location of the hospital (4.39 and 4.21, respectively).

The next investigation is to explore any demographic background of the patients associated with satisfaction. The results in Table 3 show there is almost no relationship between demographic backgrounds in satisfaction scales. For an exceptional aspect, there is a statistically significant association between satisfaction on the expertise doctor and age of NCD patients ( $p$ value $=.017^{\mathrm{a}}$ ) which is divided into 2 groups: 1 ) less than 60 years old 2) greater than or equal 60 years old. 
TABLE 2

DESCRIPTION OF SATISFACTION QUESTIONS

\begin{tabular}{llllll}
\hline \hline Satisfaction Areas & Minimum & Maximum & Mean & S.D & Class Interval \\
\hline The existing processes and procedures & & & & & \\
The simple health services processes & 1 & 5 & 4.01 & .866 & Satisfied \\
The clearness of procedure & 1 & 5 & 4.17 & .795 & Satisfied \\
The suitability of waiting time & 1 & 5 & 3.68 & .956 & Satisfied \\
The equality of getting services & 1 & 5 & 4.03 & .914 & Satisfied \\
The suitability of appointment process & 1 & 5 & 4.10 & .909 & Satisfied \\
The promptness of pharmacy & 1 & 5 & 3.77 & 1.002 & Satisfied \\
The general experience of using health services & & & & & \\
The expertise of doctor & 2 & 5 & 4.39 & .698 & Very satisfied \\
The promptness of services & 1 & 5 & 3.93 & .919 & Satisfied \\
The excellent medical equipment & 2 & 5 & 4.10 & .794 & Satisfied \\
The suitability of areas & 1 & 5 & 4.16 & .833 & Satisfied \\
The convenient travel to the hospital & 1 & 5 & 4.21 & .840 & Very satisfied \\
\hline \hline
\end{tabular}

TABLE 3

ASSOCIATION BETWEEN SATISFACTION ON NCD CLINIC SERVICES AND DEMOGRAPHIC BACKGROUND

\begin{tabular}{|c|c|c|c|c|c|}
\hline \multirow[t]{2}{*}{ Satisfaction Areas } & \multicolumn{5}{|l|}{$p$ Value } \\
\hline & Gender & Age & Education & Payment Method & Visiting Frequency \\
\hline \multicolumn{6}{|l|}{$\begin{array}{l}\text { The existing processes and } \\
\text { procedures }\end{array}$} \\
\hline The clearness of procedure & .494 & .190 & .208 & .123 & .351 \\
\hline The suitability of waiting time & .308 & .732 & .809 & .354 & .473 \\
\hline $\begin{array}{l}\text { The equality of getting ser- } \\
\text { vices }\end{array}$ & .954 & .689 & .402 & .441 & .257 \\
\hline $\begin{array}{l}\text { The suitability of appointment } \\
\text { process }\end{array}$ & .761 & .128 & .579 & .360 & .342 \\
\hline $\begin{array}{l}\text { The suitability of appointment } \\
\text { process }\end{array}$ & .638 & .566 & .390 & .436 & .210 \\
\hline The promptness of pharmacy & .440 & .966 & .481 & .541 & .264 \\
\hline \multicolumn{6}{|l|}{$\begin{array}{l}\text { The general experience of us- } \\
\text { ing health services }\end{array}$} \\
\hline The expertise of doctor & .453 & $.017^{\mathrm{a}}$ & .176 & .474 & .630 \\
\hline The promptness of services & .716 & .947 & .187 & .167 & .565 \\
\hline $\begin{array}{l}\text { The excellent medical equip- } \\
\text { ment }\end{array}$ & .855 & .245 & .748 & .555 & .804 \\
\hline The suitability of areas & .703 & .905 & .796 & .167 & .950 \\
\hline $\begin{array}{l}\text { The convenient travel to the } \\
\text { hospital }\end{array}$ & .281 & .898 & .083 & .070 & .240 \\
\hline
\end{tabular}

\section{DISCUSSION AND CONCLUSION}

In this study, we investigated the general satisfaction of NCD patients according to the utilization of medication services at the community hospital in Thailand. Our findings showed that NCD patients were satisfied with almost all satisfaction criteria from both 'general experience of using medical services' as well as 'existing process and procedure'. There are two satisfactory measures that gained extra high scores which are the expertise of the doctor and the convenience of travel. Those high satisfaction levels are the positive results of the efforts to strengthen the referral cascade system that Thai ministry has been trying to promote the capacity 
of the community hospital [12]. In contrast, the low satisfaction from the survey is related to the time spent on waiting, this could be the evidence of the system which is still operating through the manual system. Promoting the use of Information Technologies can possibly enhance the efficiency of the operations significantly. The previous studies confirmed that the waiting time is associated with patient satisfaction $[16,17]$.

The investigation was about the relationship between demographic backgrounds and satisfactory measures. We found a significant correlation between the age of NCD pa- tients and satisfaction with the expertise of doctor $(p=$ .017). The similar study about satisfaction related to the expertise of doctor was shown in [18] where women tend to score satisfaction with doctor higher than all of the rest measures. This significant result points that the doctor is the strength of public health in Thailand. Additionally, The big picture of the quality of public healthcare services in Thailand is roughly defined in the level of satisfction of NCD patients who are the largest group of patients and use the healthcare service regularly.

\section{REFERENCES}

[1] World Health Organization. Noncommunicable diseases; 2019. Available from: https://bit.ly/3amUy3i.

[2] Putri EI, Magdalena R, Novamizanti L. The detection of cervical cancer disease using an adaptive thresholding method through digital image processing. Journal of Advances in Health and Medical Sciences. 2015;1(1):30-36. doi: https: //doi.org/10.20474/jahms-1.1.4.

[3] Nikolic IA, Stanciole AE, Zaydman M. Chronic emergency: Why NCDs matter; 2011. Available from: https://bit.ly/ 2QLoPAW.

[4] Kulishov S, Lakovenko O. Differentiatial diagnosis of dermatoglyphic peculiarities in the patients with coronary heart disease and chronic kidney disease. International Journal of Health and Medical Sciences. 2015;1(2):32-36. doi: https: //doi.org/10.20469/ijhms.30002-2.

[5] Islam SMS, Purnat TD, Phuong NTA, Mwingira U, Schacht K, Fröschl G. Non-Communicable Diseases (NCDs) in developing countries: A symposium report. Globalization and Health. 2014;10(1):81.

[6] World Health Organization. Noncommunicable diseases country profiles 2018; 2018. Available from: https://bit.ly/ 2vQyor4.

[7] Bennett JE, Stevens GA, Mathers CD, Bonita R, Rehm J, Kruk ME, et al. NCD Countdown 2030: Worldwide trends in non-communicable disease mortality and progress towards Sustainable Development Goal target 3.4. The Lancet. 2018;392(10152):1072-1088. doi: https://doi.org/10.1016/s0140-6736(18)31992-5.

[8] Chastonay P, Weber D, Mattig T. A nationally coordinated health promotion program for the elderly in a Federal State, Switzerland. Journal of Population Ageing. 2019;5(5):1-14. doi: https://doi.org/10.1007/s12062-018-9237-3.

[9] Rose A, Shashidhara Y. Satisfaction on healthcare services among people living with non-communicable diseases. Manipal Journal of Nursing and Health Sciences. 2015;1(2):108-111.

[10] Prakash DB. Patient satisfaction. J Cutan Aesthet Surg 2010;. 2010;3(3):151-155. doi: https://doi.org/10.4103/ 0974-2077.74491.

[11] Khantha W, Boonkuna T, Panchakhan N, Saisueb S. Community management using Non-Communicable Disease (NCDS management using community diagnosis process in Lampang, Thailand. In: Anpor Annual Conference Proceedings, California, CA; 2017. .

[12] Thailand Ministry of Public Health. Development of the multidisciplinary manpower management criteria; 2012. Available from: https://bit.ly/2UkyFfh.

[13] Likert R. A technique for the measurement of attitudes. Rome, Italy: Archives of Psychology; 1932.

[14] Fisher RA. Statistical methods for research workers. Edinburgh, UK: Oliver and Boyd; 1950.

[15] Patcharanarumol W, Panichkriangkrai W, Wangmo S, Thammatacharee J, Uechi M, Wanwong Y. Diabetes prevention and care in the universal health coverage context: The example of Thailand. WHO South-East Asia Journal of Public Health. 2016;5(1):27-33. doi: https://doi.org/10.4103/2224-3151.206549.

[16] Atinga RA, Abekah-Nkrumah G, Domfeh KA. Managing healthcare quality in Ghana: A necessity of patient satisfaction. International Journal of Health Care Quality Assurance. 2011;4(7):548-563.

[17] Bhattacharya A, Chatterjee S, De A, Majumder S, Chowdhury KB, Basu M, et al. Patient satisfaction at a primary level health-care facility in a district of West Bengal: Are our patients really satisfied? Medical Journal. 2018;11(4):326. doi: 
https://doi.org/10.4103/2224-3151.206549.

[18] Elliott MN, Lehrman WG, Beckett MK, Goldstein E, Hambarsoomian K, Giordano LA. Gender differences in patients' perceptions of inpatient care. Health Services Research. 2012;47(4):1482-1501. doi: https://doi.org/10.1111/j. 1475-6773.2012.01389.x. 